\title{
DOES EXPOSURE TO DISTRACTION IN AN EXPERIMENTAL SETTING IMPACT DRIVER PERCEPTION OF CELL PHONE EASE OF USE AND SAFETY?
}

\author{
Angela Garabet, William J. Horrey, Mary F. Lesch \\ Center for Safety Research \\ Liberty Mutual Research Institute for Safety \\ Hopkinton, MA USA \\ E-mail: angela.garabet@libertymutual.com
}

\begin{abstract}
Summary: We examined drivers' perception of the ease and safety of cell phone use while driving before and after exposure to distraction in an experimental setting. During the study, each driver reflected on driving and task performance while engaged in conversation-like and arithmetic distraction tasks on a handsfree and hand-held cell phone. Hands-free phones were consistently rated easier to use and safer than hand-held cell phones by both age groups, despite equivalent decrements in driving performance. Younger drivers consistently rated cell phones to be easier to use and safer than did older drivers. After exposure to distraction, younger drivers' perception of the ease of use declined relative to their initial ratings; however, there was no corresponding change in the ratings of safety. In contrast, older drivers' perception of ease or safety did not change significantly post-exposure. A priori subjective ratings on various dimensions of driver skill and distraction were also examined with respect to age-related differences.
\end{abstract}

The negative effects of cell phone use on driving performance are well-documented (e.g. Brookhuis, de Vries, \& de Waard, 1991; Strayer \& Johnston, 2001; Horrey \& Wickens, 2006). In a recent survey, Wolgalter \& Mayhorn (2005) found that people who use a cell phone while driving believe that other drivers doing the same are more dangerous than they are themselves. This "optimism bias" reflects the belief that negative events are more likely to happen to others, and positive events are more likely to happen to one's self (Dalziel \& Job, 1997). There also may be an age effect on bias for certain driving activities and skills. For example, Job (1990) found that with age there was an increase in confidence in one's ability to drive after consuming alcohol.

Optimism regarding the relative risk of distraction due to in-vehicle activities, such as cell phone conversation, may be one factor that contributes to drivers' decisions to engage in these activities. For example, drivers may engage in a distracting activity because they overestimate their relative safety while doing so. As such, attitudes towards the relative safety and difficulties associated with different in-vehicle activities may be an important inroad for targeted remediation.

While the main purpose of the current study was to explore how well-calibrated drivers are to distraction effects (Horrey, Lesch \& Garabet, 2007), in this paper we explore the possibility that simple exposure to distracting activities on a cell phone in an experimental setting can shift drivers' attitudes towards cell phone safety and ease of use. Any positive shift in attitudes could help inform different driver-based initiatives, such as insight training (Creaser, Lees, \& White, 
2004; Senserrick \& Swinburne, 2001) for mitigating distraction effects. For the current analysis, we examine drivers' subjective ratings of cell phone ease of use and safety before and after the exposure to distraction.

\section{METHOD}

\section{Participants}

Participants were recruited through an advertisement in a local paper and all had a valid US driver's licence and normal or corrected-to-normal visual acuity. The forty-one participants consisted of 20 older $(\underline{M}=64$ yrs, $\underline{\mathrm{SD}}=7)$ and 21 younger drivers $(\underline{\mathrm{M}}=23 \mathrm{yrs}, \underline{\mathrm{SD}}=5)$, approximately balanced by gender. Participants were compensated at a rate of $\$ 20 / \mathrm{hr}$. There were no age-related differences in the miles driven per year (older drivers, $\underline{M}=16,130$ miles; $\underline{\text { SD }}$ =8290; younger drivers, $\underline{\mathrm{M}}=15,350$ miles; $\underline{\mathrm{SD}}=9920)$. Older drivers had roughly 46 years $(\underline{\mathrm{SD}}=9)$ of driving experience whereas younger drivers reported an average of 6 years $(\underline{\mathrm{SD}}=5)$. Fifty-five percent of older drivers admitted to using a cell phone while driving compared to $81 \%$ of younger drivers.

\section{Procedure}

Prior to the driving tasks, each participant rated the safety and ease of using a hand-held and hands-free cellular phone while driving on separate analogue scales with anchor points of "incredibily unsafe" or "incredibly difficult" to "incredibly easy" or "perfectly safe." Participants also compared themselves to the average US driver on multiple dimensions, such as safety and distractibility (modeled after Horswill, Waylen, \& Tofield, 2004).

Approximately one and a half hours of exposure to cell phone distraction was given as part of another study (Horrey et al., 2007). Drivers were given several practice laps to familiarize themselves with vehicle handling on the $0.8 \mathrm{~km}(0.5 \mathrm{mile})$ test-track. Participants were required to respond to a traffic light, pass five pacing clocks at an appropriate time and maintain laneposition. For these tasks, participants were allowed to self-select their speed with an upper limit of $48 \mathrm{kph}(30 \mathrm{mph})$. The study consisted of several treatment blocks where an auditory arthimetic or conversation task was performed while driving with either a hand-held or handsfree phone (simulated by speakers mounted behind the driver). Additionally, there was a baseline driving block with no distraction and a block for each distraction task alone with no driving. The order of exposure to phone types, distraction tasks and baseline blocks was counterbalanced.

After each block, participants rated their mental demand, mental effort, frustration, time pressure, physical demand and performance using the NASA-TLX scale (Hart \& Staveland, 1988). Participants rated their driving performance on dimensions of lane keeping, pace clock task and stop light task. In the baseline blocks, drivers reflected on the task demands without driving, or on the difficulty of the driving tasks alone.

At the end of all driving conditions, participants re-rated the safety and ease of using the devices while driving as part of the post-experimental questionnaires. The primary dependent measures were the subjective ratings (scaled from 0 to 100, with higher values indicating "easier" or 
"safer") of using each phone type while driving, assessed before and after the experiment. Age (younger, older) was a between-subjects variable while Phone Type (hands-free, hand-held), Time (pre- or post-exposure), and Dimension (safety, ease) were within-subject variables. This latter variable (Dimension) was included for examination in the context of interactions with the other variables. We also examined age-related differences in ratings of oneself relative to the average driver.

\section{RESULTS}

Both groups experienced declines in driving performance while engaged in the distracting tasks, relative to baseline, as reported in Horrey et al. 2007. There were no differences in driving and task performance between the hand-held and hands-free conditions for either age group.

A repeated measures ANOVA for the subjective ratings of ease of use and safety revealed significant main effects for Age $(\underline{F}(1,36)=8.0, \underline{p}<.008)$, Phone $(\underline{F}(1,36)=49.5, \underline{p}<.001)$ and Dimension $(\underline{F}(1,36)=12.3, \underline{p}<.001)$. Hands-free phones were rated easier to use and safer than hand-held cell phones by both age groups (both before and after the experiment). As shown in Figure 1, younger drivers rated the concurrent driving and cell phone activities as safer and easier than did older adults. As noted previously, we were mainly interested in the influence of exposure on ratings. This effect was manifested in a significant three-way interaction of Age, Time and Dimension $(\underline{F}(1,36)=4.3, \underline{p}<.05$; see Figure 1$)$. For younger drivers, there was a significant decrease in the ease ratings following exposure to distraction $(\mathrm{p}<.04)$; however, there was no corresponding shift in the safety ratings for either phone type $(\underline{p}<.50)$. That is, although younger drivers reported that concurrent cell phone tasks were more difficult following exposure, they did not report a decrease in relative safety (note that the slight shift shown in Figure 1 is in the opposite direction). In contrast, for older drivers, there was no shift in the ease or safety ratings after exposure to distraction $(\mathrm{p}<.90 \& \mathrm{p}<.70$; respectively).
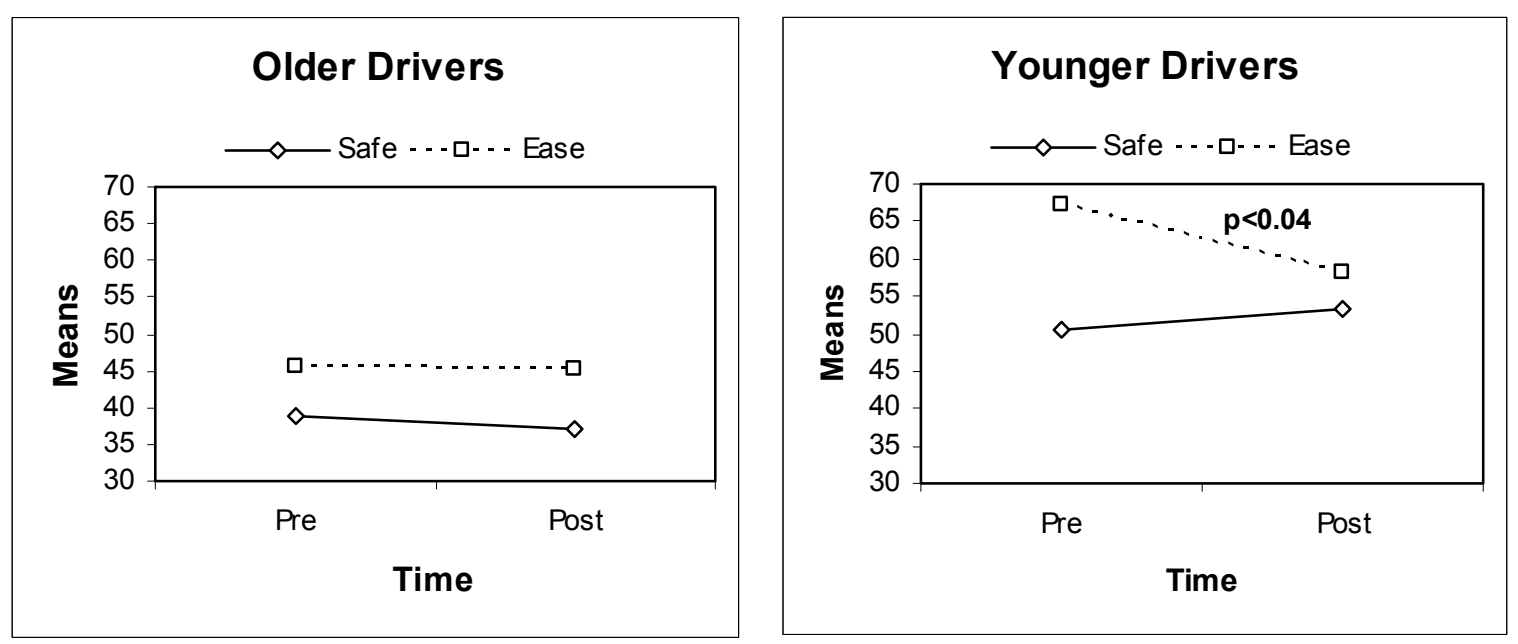

Figure 1. Ease and safety ratings for younger and older drivers across both phone types 
We also examined subjective ratings of abilities and distraction effects, measured prior to engaging in the distracting tasks. The scales are shown in Table 1. For example, participants rated how often they deal with distracting tasks while driving on a score of 1 (never) to 5 (always). Confidence in dealing with distractions was rated along a continuum with anchor points of 0 (incredibly uncomfortable) and 100 (perfectly comfortable). All other variables were scored out of 100, with 0 being much less (or worse) than average and 100 much more (or better) than average. Compared to the average driver, both younger and older drivers rated themselves more favorably on all dimensions.

Table 1. Age-related differences in subjective ratings

\begin{tabular}{|l|c|c|c|c|}
\hline & Older & Younger & $\begin{array}{c}\text { Mann } \\
\text { Whitley }(\boldsymbol{U})\end{array}$ & $\boldsymbol{p}$ \\
\hline How often do you deal with distracting tasks? & $2.8(0.7)$ & $3.2(0.8)$ & 146.5 & .07 \\
\hline $\begin{array}{l}\text { How confident (comfortable) are you in } \\
\text { dealing with distracting tasks? }\end{array}$ & $82.9(10.1)$ & $79.5(19.5)$ & 201.5 & .82 \\
\hline How distractible are you? & $19.8(14.7)$ & $34.8(21.8)$ & 116.0 & $<.01$ \\
\hline $\begin{array}{l}\text { How good are you at dealing with distraction } \\
\text { while driving? }\end{array}$ & $70.3(21.7)$ & $69.1(16.1)$ & 190.0 & .60 \\
\hline How safe are you? & $80.2(13.8)$ & $65.7(19.4)$ & 107.5 & $<.01$ \\
\hline How skillful are you? & $75.9(12.8)$ & $65.4(18.3)$ & 139.0 & .06 \\
\hline How fast do you tend to drive? & $58.1(13.1)$ & $58.4(15.4)$ & 209.0 & .98 \\
\hline $\begin{array}{l}\text { How likely are you to have an accident in the } \\
\text { next 3 years? }\end{array}$ & $15.8(14.4)$ & $28.8(25.7)$ & 152.5 & .13 \\
\hline
\end{tabular}

Note. Standard deviations are shown in parentheses.

Interestingly, while there were age-related differences in the perception of ease and safety of cell phone use (as discussed above) there were no differences between the age groups in self-reported ability to deal with distractions and general comfort in dealing with distracting tasks while driving. Younger drivers reported slightly greater frequency in dealing with distracting tasks while driving (a marginally significant effect) and greater cell phone use while driving $\left[\chi^{2}(1)=4.3, \underline{\mathrm{p}}<.04\right]$. However, older adults rated themselves as less likely to be distracted in general while driving. Older drivers also provided higher ratings of overall driving skill and safety while driving than the younger drivers. Thus, despite lower self-rated driving skill and higher self-rated distractibility, younger drivers rated cell phone ease of use and safety higher than their older counterparts. The age groups did not differ in terms of the perceived risk of an accident in the next three years.

For older drivers, confidence in dealing with distracting tasks was significantly correlated to the reported ability to deal with distraction while driving $(r=.44, \mathrm{p}<.05)$, the level of distractibility while driving $(r=-.59, \mathrm{p}<.006)$, as well as general vehicle control (fast $(r=-.57, \mathrm{p}<.009)$, safe $(r=.62, \underline{\mathrm{p}}<.003)$, skillful $(r=.62, \underline{\mathrm{p}}<.003)$, and accident likelihood $(r=-.45, \underline{\mathrm{p}}<.05)$. In contrast, for younger drivers, confidence in dealing with distracting tasks was correlated only to the ability to deal with distraction while driving, $(r=.58, \mathrm{p}<.006)$. This might suggest that for young people there is a disconnect between perceived ability to handle distractions and perceived driving skill. For younger drivers, increased skill was only associated with an increase in the likelihood of driving fast $(r=.47, \underline{p}<.03)$, whereas there was no corresponding correlate 
for older drivers. Self-reported frequency of dealing with distracting tasks did not correlate significantly with any of the other ratings, for either age group.

\section{DISCUSSION}

Throughout the study, participants were asked to reflect on both driving and task performance during exposure to distracting cell phone tasks while driving. Even after exposure, participants still perceived that hands-free phones were easier and safer than hand-held phones-even though performance results showed comparable decrements for both (consistent with Strayer \& Johnston, 2001). Similarly, White, Eiser \& Harris (2004) found a large discrepancy between the risk perception of using hand-held devices and hands-free phones. It is possible that hands-free cell phones promote an inappropriate perception of safety - a finding that may be ironic given that most legislative bans target hand-held phones, while permitting hands-free devices.

For younger drivers, there was a downwards shift in the ease of use ratings for both cell phone types following exposure; however, there was no corresponding shift in safety ratings. This pattern suggests that these might not be correlated constructs. It is possible that young drivers originally overestimated the ease of using a cell phone while driving and that the exposure allowed them to modifiy their initial impressions.

While young people rated themselves as being more prone to distraction while driving and less skilled, they nevertheless estimated ease and safety of both cell phone types higher than older drivers did. In contrast, for older adults, there was no shift in any of the ratings. Older drivers might have initially given more conservative ratings of cell phone ease and safety despite rating themselves as more skilled drivers. Kruger and Dunning (1999) found that skill improvement helped people to recognize limitations of their abilities. This might be the same with older drivers who have more driving experience and skill, and who might act more cautiously when it comes to dealing with distractions.

For older drivers, the ability to deal with distractions was correlated with general distractibility, as well as perceived safety and skill as a driver. Whereas for younger drivers, confidence and ability to deal with distractions was not related to general distractibility or to self-reported driving skills. In general, people have a tendency to rate themselves better than the average driver in terms of skill (e.g., Horswill et al., 2004), safety (e.g., Svenson, 1981, Delhomme, 1991) and accident likelihood (e.g., Svenson, Fischhoff \& MacGregor, 1985). Consistent with these results, an overestimation bias was found for all rating dimensions across both age groups. When designing driver training interventions, people might not think safety messages apply to them because of an overestimation of their own abilities (Job, 1990). Because of the different pattern of correlations between distraction and driving skill for the different age groups, interventions might need to target different dimensions of bias for each age group separately. For example, for younger drivers, perceived ability to deal with distraction, vehicle skill and general safety might be important dimensions to target.

Since these results were not the main focus of the experiment, performance feedback was not given, and therefore participants might not have been fully aware of the consequences of distraction effects of the cell phone tasks. In addition, the study took place on a closed track with 
no traffic and minimal risk. As such, the distracting effects might not have posed a large enough risk for appreciation of cell phone ease of use and safety. Thus, these preliminary results suggest that simple exposure to distraction may impact some attitudes of some drivers. Whether these shifts would have a lasting impact on attitudes or whether these would have any direct influence on behaviors is unknown. At best, these results are suggestive. A more targeted approach is merited, involving a closed feedback loop (in which drivers are aware of any driving deficits), as well as a more comprehensive follow-up, in order to assess the impact on subsequent driving behaviors.

\section{CONCLUSIONS}

Previous work has suggested that people who use phones while driving may overestimate their driving skills and ability to deal with distractions (Wogalter \& Mayhorn, 2005) and underestimate their chance of getting into an accident compared to others (White et al., 2004). Younger drivers initially acknowledged some limitations, compared to older drivers (e.g., more easily distracted, less skilled and more likely to be involved in an accident). Nevertheless, they perceived concurrent cell phone use and driving to be easier and safer than their older, more experienced counterparts did. The two age groups did not differ in their self-reported ability to deal with distractions. After exposure to distracting tasks in an experimental setting, there was a significant change in the perception of ease of hand-held phone use while driving by younger drivers. Initially, younger drivers might have over-estimated the ease of using a cell phone while driving, reflecting an optimism bias that might be limited to secondary tasks. Indeed, for younger drivers, after exposure to distraction, there was a significant change in the perception of ease of use, but no corresponding shift in safety rating. Older drivers did not shift their ease or safety rating post-exposure. The difference in shift pattern post-exposure, suggests that the concepts of ease and safety may not necessarily be correlated and may differ amongst age groups (Dukic et al., 2006).

\section{ACKNOWLEDGMENTS}

The authors are grateful to Peter Teare, Eric Jones, Richard Holihan, and Ed Correa for their upkeep and maintenance of the instrumented van, and to Michelle Robertson for comments.

\section{REFERENCES}

Brookhuis, K.A., de Vries, G., \& de Waard, D. (1991). The effects of mobile telephoning on driving performance. Accident Analysis and Prevention, 23(4), 309-316.

Creaser, J.I., Lees, M.N., \& White, C. (2004). The effect of insight and error-based feedback on young drivers' following behavior and confidence. Proceedings of the Human Factors and Ergonomics Society 48th Annual Meeting, Santa Monica, CA, 2261-2265.

Dalziel, J.R., \& Job, R.F.S. (1997). Motor vehicle accidents, fatigue and optimism bias in taxi drivers. Accident Analysis and Prevention, 29(4), 489-494.

Delhomme, P. (1991) Comparing one's driving with others': Assessment of abilities and frequency of offences. Evidence for a superior conformity of self-bias? Accident Analysis and Prevention, 23(6), 493-508. 
Dukic, T., Hanson, L., \& Falkmer, T. (2006). Effect of drivers' age and push button locations on visual time off road, steering wheel deviation and safety perception. Ergonomics, 49(1), 78-92.

Hart, S.G., \& Staveland, L.E. (1988). Development of NASA-TLX (Task Load Index): Results of experimental and theoretical research. In P.A. Hancock \& N. Meshkati (Eds.), Human Mental Workload. Amsterdam: North Holland.

Horrey, W.J., \& Wickens, C.D. (2006). Examining the impact of cell phone conversations on driving using meta-analytic techniques. Human Factors, 48(1), 196-205.

Horrey, W.J., Lesch, M.F., \& Garabet, A. (2007). Awareness of performance decrements due to distraction in younger and older drivers. Proceedings of the $4^{\text {th }}$ International Driving Symposium on Human Factors in Driver Assessment, Training and Vehicle Design, Stevenson, WA.

Horswill, M.S., Waylen, A.E., \& Tofield, M.I. (2004). Drivers' ratings of different components of their own driving skill: A greater illusion of superiority for skills that relate to accident involvement. Journal of Applied Social Psychology, 34(1), 177-195.

Job, R.F. (1990). The application of learning theory to driving confidence: the effect of age and the impact of random breath testing. Accident Analysis and Prevention, 22(2), 97-107.

Kruger, J. \& Dunning, D. (1999). Unskilled and unaware of it: How difficulties in recognizing one's own incompetence lead to inflated self-assessments. Journal of Personality and Social Psychology, 77(6), 1121-1134.

Senserrick, T.M., \& Swinburne, G.C. (2001). Evaluation of an insight driver training program for young drivers (Report No. 186). Victoria, Australia: Monash University Accident Research Centre.

Svenson, O. (1981). Are we all less risky and more skillful than our fellow drivers? Acta Psychologica, 47, 143-148.

Svenson, O., Fischhoff, B., \& MacGregor, D. (1985). Perceived driving safety and seatbelt usage. Accident Analysis and Prevention, 17(2), 119-133.

Strayer, D.L., \& Johnston, W.A. (2001). Driven to distraction: Dual-task studies of simulated driving and conversing on a cellular phone. Psychological Science, 12(6), 462-466.

White, M.P., Eiser, J.R., \& Harris, P.R. (2004). Perceptions of mobile phone use while driving. Risk Analysis, 24(2), 323-334.

Wogalter, M.S., \& Mayhorn, C.B. (2005). Perceptions of driver distraction by cellular phone users and non-users. Human Factors, 47(2), 455-467. 